\title{
Treatment Options for Refractory Kawasaki Disease
}

\author{
Anuja Oli ${ }^{1}$, Hongzhu Lu${ }^{1 *}$, Dhiraj Khati ${ }^{2}$ \\ ${ }^{1}$ Department of Pediatrics, First Clinical College, Yangtze University, Jingzhou, China \\ ${ }^{2}$ Department of Cardiology, First Clinical College, Yangtze University, Jingzhou, China \\ Email: *lucas215@163.com
}

How to cite this paper: Oli, A., Lu, H.Z. and Khati, D. (2020) Treatment Options for Refractory Kawasaki Disease. Yangtze Medicine, 4, 28-38.

https://doi.org/10.4236/ym.2020.41003

Received: June 4, 2019

Accepted: September 14, 2019

Published: September 17, 2019

Copyright (c) 2020 by author(s) and Scientific Research Publishing Inc. This work is licensed under the Creative Commons Attribution International License (CC BY 4.0).

http://creativecommons.org/licenses/by/4.0/

\begin{abstract}
Kawasaki Disease (KD) is a self-limiting systemic vasculitis common among children under five years of age. Diagnosis of the disease is made primarily from the clinical features presented during the illness. Coronary artery aneurysm (CAA) is the main complication of this disease which can be prevented largely by the early diagnosis and administration of IVIG (Intravenous Immunoglobulin). Even with first dose of IVIG up to $10 \%-20 \%$ of patients develop refractory Kawasaki Disease, i.e., remain unresponsive to initial IVIG treatment. Second dose of IVIG is recommended treatment for refractory Kawasaki Disease but other alternative treatments are also being considered to lower the risk of complications. Different drugs are still in trial phase and some others have limited studies on larger population. Most of the study reports that involved newer drugs have limited patients or are from single centers which are very hard to apply to larger population. We will review general treatment approach in refractory Kawasaki disease.
\end{abstract}

\section{Keywords}

Refractory Kawasaki Disease, Intravenous Immunoglobulin, Coronary Artery Aneurysm

\section{Introduction}

Kawasaki disease is an acute, self-resolving systemic vasculitis [1], that is commonly seen in children under the age of five years. Before the term Kawasaki disease (KD), it was reported as syndrome of mucocutaneous lymph node with infantile polyarteritis nodosa which was common among younger Asian population. Tomisaku Kawasaki first reported 50 cases at the end of 1966 and got them ${ }^{\star}$ Corresponding author. 
published in Japanese Journal of Allergy in the year 1967 with the title "Acute febrile mucocutaneous lymph node syndrome: clinical observation of 50 cases" [2]. This disease primarily affects medium sized arteries which complicate into acquired childhood cardiac disease. Kawasaki disease has replaced acute rheumatic fever as leading cause of childhood acquired cardiac disease in Japan, the United States and in Europe [3].

\subsection{Diagnosis}

Diagnosis of Kawasaki is based on recognition of temporal features of clinical features presented during the illness. Diagnostic criteria [4] of Kawasaki consist of fever lasting for at least five days along with any four among these 5 clinical features, 1) Bilateral bulbar conjunctival injection; 2) Oral mucous membrane changes, including injected or fissured lips, injected pharynx, or strawberry tongue; 3) Peripheral extremity changes, including erythema of palms or soles, edema of hands or feet (acute phase), and periungual desquamation (convalescent phase); 4) Polymorphous rash; and 5) Cervical lymphadenopathy (at least 1 lymph node $>1.5 \mathrm{~cm}$ in diameter). Patient fulfilling these criteria are diagnosed with complete Kawasaki disease and those not fulfilling these criteria but having 2 or 3 criteria and a strong clinical suspicion of KD [5] can further be evaluated with the help of laboratory and echocardiographic evaluation and if further criteria fulfilled then those are diagnosed as incomplete Kawasaki disease.

\subsection{Etiology}

The etiology of KD remains unknown. Many theories have been proposed based on genetic, infectious and immune dysregulation. In Asian population several single nucleotide polymorphisms associated with susceptibility of $\mathrm{KD}$, including FCGR2A, CASP3, HLA, BLK, ITPKC and CD40 [6]. In European population FCFR2A and ABCC4 have also been found to be susceptible to KD [7] [8]. Bacterial and viral infections like retrovirus, EPV, coronavirus, staphylococcal, streptococcal superantigens act like an infectious trigger of $\mathrm{KD}$. These superantigens act by binding to $\mathrm{V} \beta$ regions of the $\mathrm{T}$ receptor and induce a widespread immunologic response resulting in release of TNF- $\alpha$, IL- $1 \beta$, IL- 6 and IL- $\gamma$ and these are felt to be directly related to fever, mucosal changes and desquamation in $\mathrm{KD}$ [9]. $\mathrm{KD}$ is classically considered to be due to immune dysregulation. It has been proposed that $\mathrm{KD}$ is similar to autoimmune disease in pathogenesis. $\mathrm{T}$ cells have been implicated in the inflammatory cascade in $\mathrm{KD}$, with an emphasis on negative regulator of $\mathrm{T}$ cell activation. Loss of this regulator causes an increase in $\mathrm{T}$ cell activation and cytokine production and is hypothesized to have increased risk of coronary artery lesions [10].

\subsection{Epidemiology}

Incidence of Kawasaki disease is high in east Asian countries but reported all around the world. Fewer cases have been reported from Africa [11] and Latin 
America [12]. Japan has the highest incidence of KD. Incidence rate was 322.45 patients per 100,000 children aged 0 - 4 years [13]. Incidence in South Korea was 194.9 per 100,000 children under five years of age in the year 2012 [14]. Taiwan reported to have average incidence of KD from 1997 to 2011 be 45.2 per 100,000 children under 5 years [15]. Incidence of $\mathrm{KD}$ in China was 40.9 to 55.1 per 100,000 children under five years which was based on study conducted from 2000-2004 in Beijing [16]. Hong Kong showed incidence of 39 per 100,000 children under 5 years [17] from 1994-2000. Recent study [18] that included patients admitted with the diagnosis of KD from 2000 to 2011 showed annual incidence of 74 children per 100,000 children under five years. In the United States it was 20.8 per 100,000 children under five years in 2006 [19]. Europe has annual incidence of 8.39 per 100,000 children under five years. Ireland has the highest incidence of KD in Europe 15.2 per 100,000 children under five years of age [20]. In western Australia a study [21] showed annual incidence of 2.82 per 100,000 children under five years in 1980-1989, 7.76 in 1990-1999 and 9.34 in 2000-2009. In New Zealand, a study [22] from January 2001 to December 2002 found annual incidence rate of $8 / 100,000$ cases in children under five years.

\subsection{Complications}

The most serious complications of KD are cardiovascular complications. It may cause coronary artery aneurysm (CAA) and myocardial abnormalities. It affects medium size blood vessels, so coronary arteries are one of the most affected arteries. Dilatation of coronary arteries $>4 \mathrm{~mm}$ is considered dilation and when it is more than $8 \mathrm{~mm}$ it is called giant CA aneurysm. Other cardiac problems like decreased myocardial contractility, valvular regurgitation (mild) and pericardial effusion can also occur. CAA classification is done according to the Z-scoring system of the internal diameter of the lumen. CAA occurs in $25 \%-30 \%$ untreated patients [23]. Even with appropriate treatment there is up to $5 \%$ chances of CAA and CAA larger than $6 \mathrm{~mm}$ has strong relation with the myocardial ischemia [24].

\subsection{Initial Treatment}

Recommended initial therapy for KD is Intravenous Immunoglobulin (IVIG) 2 $\mathrm{g} / \mathrm{kg}$ and aspirin (Acetylsalicylic acid or ASA) 30 to $50 \mathrm{mg} / \mathrm{kg} /$ day (In Japan) - 80 $100 / \mathrm{mg} / \mathrm{kg} /$ day in four divided doses. IVIG is given over $8-12$ hours in a single infusion and has better outcome if given in 7 - 10 days of illness. Same dose of IVIG and aspirin is given to complete and incomplete Kawasaki disease. This treatment is known to drop the occurrences of CAAs from $20 \%-25 \%$ to $3 \%-5 \%$ [25].

\section{Refractory Kawasaki Disease}

Those patients who do not respond with initial treatment are considered to be a refractory KD. Initial IVIG resistant is seen in around $10 \%-20 \%$ of total KD patients whom IVIG is administered [5]. Patients having recrudescent fever or persistent fever 36 hours after the end of IVIG administration are considered to be 
resistant to IVIG. Other causes of fever should also be considered and thoroughly evaluated. IVIG resistant patients have high chances of having coronary artery aneurysms. Treatment algorithm from AHA has suggested use of glucocorticoids (prednisolone $2 \mathrm{mg} / \mathrm{kg} /$ day IV or orally in three divided doses for 10 days, then $1 \mathrm{mg} / \mathrm{kg} /$ day for 5 days) for patients having high risk for IVIG resistance during initial treatment along with IVIG and aspirin. Risk stratification is different for Japanese and non-Japanese population. Clear causes of IVIG resistant are still unknown but some risk scoring systems have been developed to predict the occurrences of IVIG resistant. Scoring system like Egami, Kobayashi, Sano, San Diego, Harada and Formosa are being used to predict the occurrences of IVIG resistance. Egami, Sano and Kobayashi are more common scoring systems have sensitivity of $78 \%, 86 \%$ and $77 \%$ in Japanese population [26] but has lower sensitivity in other population. These scoring systems use different lab variables, age, duration of fever and initiation of treatment as risk factors for their point system. Patient may benefit from adjuvant therapy when considered high risk for IVIG resistant.

\section{Treatment after Resistant to Initial IVIG Treatment}

$10 \%-20 \%$ fail to respond to initial IVIG treatment. Presence of persistent fever is an indication for further treatment. Other causes of fever should also be looked for. Second dose of IVIG $2 \mathrm{~g} / \mathrm{kg}$ is recommended if fever persists after 36 hours of end of first IVIG infusion. Patient again evaluated after 36 hours after end of infusion and if there is persistent fever then it is considered to be resistant to treatment with IVIG. Some clinician has used other agents like infliximab instead of IVIG for retreatment that showed lower days of hospitalization but data demonstrating beneficial effects on CAs were minimal [27].

\section{Treatment Options after Failed Second IVIG Infusion}

IVIG infusion more than $4 \mathrm{~g} / \mathrm{kg}$ is not recommended in children due to risk of causing hemolytic anemia in children. Furthermore, other treatment options should be looked for ongoing vasculitis within the body to minimize the complications. Aspirin, IVIG and glucocorticoids are commonly used agents for KD but when there is failure with second dose of IVIG other drugs like tissue necrosis factor-alpha inhibitors, immunosuppressive agents and plasmapheresis can be considered. Figure 1 illustrates the available and optional treatment for Kawasaki Disease and IVIG resistant Kawasaki Disease. Though new drugs have shown safe and effective results in small studies but their therapeutic utility remains unproven [28]. Table 1 shows treatment options for Refractory Kawasaki Disease that are currently available.

\subsection{Glucocorticoid Therapy}

Glucocorticoid therapy can be given along with first IVIG infusion in a high risk patient. Furthermore, it can also be given after initial IVIG resistant as an alternative 


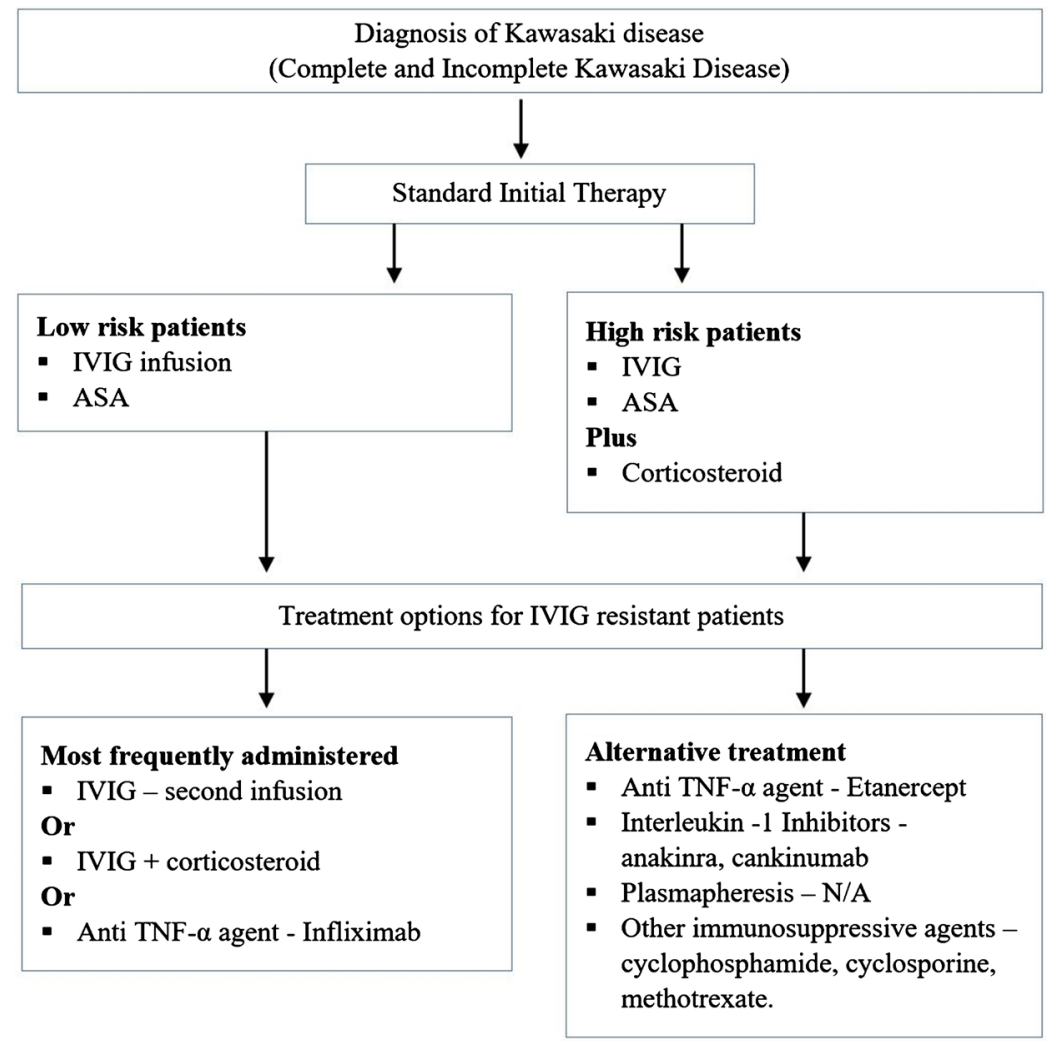

IVIG: Intravenous Immunoglobulin, ASA: Acetylsalicylic Acid

TNF: Tumor Necrosis Factor

Figure 1. Treatment options for Kawasaki Disease and Refractory (IVIG resistant) Kawasaki Disease.

treatment or along with second IVIG treatment. Methylprednisolone $30 \mathrm{mg} / \mathrm{kg}$ per day for up to 3 days after failed second dose of IVIG acts as a good alternate agent. Alternately use of prednisone/prednisone IV/oral starting with 1 - 2 $\mathrm{mg} / \mathrm{kg} /$ day can also be given. Prednisolone dose should be given at least to 15 days. In a study [29] conducted in Japan on 63 patients who didn't respond to initial IVIG treatment, 44 patients those not responding with first dose of IVIG were treated with methylprednisolone $(30 \mathrm{mg} / \mathrm{kg}$ per day for 3 days) and 19 remaining treated with second dose of IVIG. Among 44 patients those treated with methylprednisolone 34 had resolutions of fever. In other group with second dose of IVIG group 12 patients out of 19 patients had resolution of fever. All patients who had not responded with methylprednisolone or second IVIG infusion were again given another course of methylprednisolone. All together 8 patients had CAAs. 5 out of 10 who failed to respond to methylprednisolone and 2 out of 7 who failed to respond to second dose of IVIG developed CAAs.

\subsection{Tumor Necrosis Factor (TNF)-Alpha Inhibition}

Elevations of tissue necrosis factors are characteristic feature of $\mathrm{KD}$, so anti-TNF- $\alpha$ agents such as infliximab and etanercept have been studied in the treatment of $\mathrm{KD}$. These agents can rapidly normalize laboratory markers of 
Table 1. Currently available treatment options for Refractory Kawasaki Disease.

\begin{tabular}{|c|c|c|c|}
\hline Drugs & Dose & Remarks & Reference \\
\hline 1. IVIG & $2 \mathrm{~g} / \mathrm{kg} 8$ - 10 hours, single infusion & Recommended treatment in IVIG resistant KD. & {$[5]$} \\
\hline 2. IVIG + Corticosteroid & $\begin{array}{l}\text { Methylprednisolone } 30 \mathrm{mg} / \mathrm{kg} \text { per } \\
\text { day for up to } 3 \text { days or prednisolone } \\
1-2 \mathrm{mg} / \mathrm{kg} / \text { day for at least } 15 \text { days }\end{array}$ & Commonly used alternative treatment. & {$[5]$} \\
\hline \multicolumn{4}{|l|}{ 3. Anti (TNF) - alpha agent } \\
\hline $\begin{array}{l}\text { - Infliximab } \\
\text { - IVIG + Infliximab }\end{array}$ & $\begin{array}{l}5 \mathrm{mg} / \mathrm{kg} \text { IV } 2 \text { hours } \\
\text { IVIG + Infliximab } 5 \mathrm{mg} / \mathrm{kg} \mathrm{IV}\end{array}$ & $\begin{array}{l}\text { Progression of CAAs was similar in both groups. These } \\
\text { agents can rapidly normalize laboratory markers of } \\
\text { inflammation. }\end{array}$ & [30] \\
\hline - Etanercept & $0.8 \mathrm{mg} / \mathrm{kg} 3$ doses & $\begin{array}{l}\text { Still in research phase for IVIG resistant. Trial of etanercept } \\
\text { as adjuvant with IVIG in initial therapy showed no decrease } \\
\text { in IVIG resistant. }\end{array}$ & [31] \\
\hline \multicolumn{4}{|c|}{ 4. Interleukin-1 (IL-1) Inhibition } \\
\hline $\begin{array}{l}\text { - anakinra } \\
\text { - canakinumab }\end{array}$ & $2-6 \mathrm{mg} / \mathrm{kg} /$ day by s/c injection & $\begin{array}{l}\text { Are in trial phase. Initial reports suggesting these drugs } \\
\text { are safe to children but data regarding their efficacy is still } \\
\text { not available. }\end{array}$ & [32] [33] \\
\hline 5. Plasmapheresis & Plasma exchange & $\begin{array}{l}\text { Complex and suggested to use in children with all other } \\
\text { failed pharmacologic treatment. Showed benefit in some } \\
\text { small sized studies. Not applicable. }\end{array}$ & $\begin{array}{l}{[34][35]} \\
{[36]}\end{array}$ \\
\hline \multicolumn{4}{|c|}{ 6. Other Immunosuppressive Agents } \\
\hline - cyclophosphamide & - & Studies been carried out in a very limited numbers of & [37] [38] \\
\hline - cyclosporine & - & patients and centers. Studies are still going on these drugs & {$[1]$} \\
\hline - Tocilizumab & - & $\begin{array}{l}\text { but due to its toxicity these are not front lines drugs for } \\
\text { refractory KD. }\end{array}$ & \\
\hline - Methotrexate & $\begin{array}{l}{[10 \mathrm{mg} / \text { body surface area }(\mathrm{BSA})]} \\
\text { till fever subside }\end{array}$ & $\begin{array}{l}\text { Showed improvement in reduction of symptoms but no } \\
\text { in improvement or prevention of CAL }\end{array}$ & [39] \\
\hline
\end{tabular}

inflammation in IVIG-resistant cases of KD. In a randomized multicenter trial [30], initial IVIG resistant were given infliximab (5 mg/kg IV) or second dose of IVIG. Fever resolved in 11 out of 12 patients with infliximab group and 8 out of 12 patients another group who were given second dose of IVIG. Progression of CAAs was similar in both groups. Etanercept is another anti-TNF- $\alpha$ agent which is under the study for the treatment of primary $\mathrm{KD}$. Not many reports have been published regarding the use of etanercept in KD in IVIG resistant group. A double-blind multicenter trial, where patients were given etanercept $(0.8 \mathrm{mg} / \mathrm{kg} ; \mathrm{n}$ $=100)$ or placebo $(\mathrm{n}=101)$ subcutaneously immediately after IVIG infusion first dose. It was given as adjuvant therapy to initial IVIG treatment and overall IVIG resistant was $17.4 \%$ in both groups. Etanercept group had 13\% resistant in compare to $22 \%$ in placebo group. It concluded that there was no significant decrease in IVIG resistance in overall population. However, etanercept reduced IVIG resistance in patients $>1$ year of age and also marginally improvement in AAs [31].

\subsection{Interleukin-1 (IL-1) Inhibition}

IL-1 elevation has been reported in Kawasaki disease that may be linked to co- 
ronary and myocardial complications. IL - 1 inhibitors like anakinra and cankinumab are in trial for treating refractory $\mathrm{KD}$. Initial reports suggesting these drugs are safe to children but data regarding their efficacy is still not available [32]. In a study conducted by Dusser P et al. [33] IL-1 blockade treatment such as anakinra showed successful improvement in myocarditis and aneurysm that was formed in a mouse model of KD.

\subsection{Plasmapheresis}

Plasmapheresis is effective in acute inflammatory conditions. Kawasaki disease is an acute inflammatory disease so plasmapheresis is ideal condition for this intervention. Kawasaki itself is self-limiting disease and plasmaphereses being very complex and hazardous conditions [34], it is suggested to use it in those children who have undergone all the other pharmacologic treatment and still having active vasculitis. In a study [35] which included 10 patients from 2006-2015 with failed IVIG and complicated by coronary artery lesions were treated with plasma exchange. 6 out of 10 patients had their coronary artery lesions at normal level after one of treatment. No stenosis in 9 out of 10 patients. Another study involving 4 patients also concluded plasma exchange be effective for refractory Kawasaki disease [36].

\section{Summary and Prospective}

Since first coining the name "Kawasaki Disease" by Tomisaku Kawasaki 52 years back it has now become one of the important rheumatological vasculitis diseases to be considered on pediatric patients mainly under five years of age. With the growing knowledge and awareness of the disease more numbers of patients have been diagnosed and reported. This disease is mainly affecting the children of east Asian countries like Japan, South Korea, and China but is seen all over the world. Less patient numbers were reported from Latin America and Africa but with growing awareness number of patients may increase in the future. Chances of misdiagnosing are high in developing countries due to its similarities with other infectious diseases like measles and rubella. Early IVIG is highly effective in preventing its coronary complication so proper diagnosis is very important. Global awareness is necessary for Kawasaki Disease to prevent its coronary complications mainly in the countries where there are fewer incidences which may be due to low awareness towards disease.

Initial IVIG is a standard treatment method for the KD but around 10\% - 20\% patients fail to respond and develop refractory Kawasaki disease. Patient can also be evaluated for risk factors before the initiation of first IVIG to lower the risk of resistance and continued follow-up. Treatment algorithm has also suggested using adjuvant glucocorticoids in those patients having high chances of IVIG resistant. Patients those are resistant to initial dose of IVIG are recommended to have second dose of IVIG. Alternately, methylprednisolone, prednisolone and infliximab have also been used instead of second dose of IVIG and have shown 
good outcomes on responding fever but have not shown more beneficial effects on CAAs. These drugs can also be used after the failure of second IVIG infusion. Furthermore, immunosuppressive, plasmapheresis are also alternatives but due to their limited studies and more toxicity and hazardous procedures, they should be limited to those refractory cases that were first treated with recommended pharmacologic agents.

\section{Conflict of Interest}

We declare no conflicts of interest regarding the publication of this paper.

\section{References}

[1] Rowley, A.H. and Shulman, S.T. (2010) Pathogenesis and Management of Kawasaki Disease. Expert Review of Anti-Infective Therapy, 8, 197-203. https://doi.org/10.1586/eri.09.109

[2] Kawasaki, T. and Naoe, S. (2014) History of Kawasaki Disease. Clinical and Experimental Nephrology, 18, 301-304. https://doi.org/10.1007/s10157-013-0877-6

[3] Chang, C.L., Wong, C.S., Yang, Y.C. and Chiu, N.C. (2018) Influence of Latitude on the Prevalence of Kawasaki Disease: A Retrospective Cohort Study from the Taiwan National Health Insurance Database and Review of the Literature. International Journal of Environmental Research and Public Health, 15, 845. https://doi.org/10.3390/ijerph15050845

[4] Ayusawa, M., Sonobe, T., Uemura, S., Ogawa, S., Nakamura, Y., et al. (2005) Revision of Diagnostic Guidelines for Kawasaki Disease (the 5th Revised Edition). Pediatrics International: Official Journal of the Japan Pediatric Society, 47, 232-234. https://doi.org/10.1111/j.1442-200x.2005.02033.x

[5] McCrindle, B.W., Rowley, A.H., Newburger, J.W., Burns, J.C., Bolger, A.F., et al. (2017) Diagnosis, Treatment, and Long-Term Management of Kawasaki Disease: A Scientific Statement for Health Professionals from the American Heart Association. Circulation, 135, e927-e999. https://doi.org/10.1161/CIR.0000000000000484

[6] Esper, F., Shapiro, E.D., Weibel, C., Ferguson, D., Landry, M.L. and Kahn, J.S. (2005) Association between a Novel Human Coronavirus and Kawasaki Disease. The Journal of Infectious Diseases, 191, 499-502. https://doi.org/10.1086/428291

[7] Khor, C.C., Davila, S., Breunis, W.B., Lee, Y.C., Shimizu, C., et al. (2011) Genome-Wide Association Study Identifies FCGR2A as a Susceptibility Locus for Kawasaki Disease. Nature Genetics, 43 1241-1246. https://doi.org/10.1038/ng.981

[8] Khor, C.C., Davila, S., Shimizu, C., Sheng, S., Matsubara, T., et al. (2011) Genome-Wide Linkage and Association Mapping Identify Susceptibility Alleles in ABCC4 for Kawasaki Disease. Journal of Medical Genetics, 48, 467-472. https://doi.org/10.1136/jmg.2010.086611

[9] Meissner, H.C. and Leung, D.Y. (2000) Superantigens, Conventional Antigens and the Etiology of Kawasaki Syndrome. The Pediatric Infectious Disease Journal, 19, 91-94. https://doi.org/10.1097/00006454-200002000-00001

[10] Yeung, R.S. (2010) Kawasaki Disease: Update on Pathogenesis. Current Opinion in Rheumatology, 22 551-560. https://doi.org/10.1097/BOR.0b013e32833cf051

[11] Animasahun, B.O., Adekunle, M., Kushimo, O. and Fadipe, C. (2017) The Diagnosis of Kawasaki Disease among Nigerian Children: A Nightmare for the Caregivers and the Doctors. Journal of Public Health and Emergency, 1, 69. 
https://doi.org/10.21037/jphe.2017.06.06

[12] Gonzalez-Mata, A., Ulloa-Gutierrez, R., Brea, J., Soza, G. and Tremoulet, A.H. (2014) Origin and Importance of the Latin American Kawasaki Disease Network (REKAMLATINA). Revista Chilena de Infectologia, 31, 330-332. https://doi.org/10.4067/S0716-10182014000300012

[13] Sano, T., Makino, N., Aoyama, Y., Ae, R., Kojo, T., Kotani, K., Nakamura, Y. and Yanagawa, H. (2016) Temporal and Geographical Clustering of Kawasaki Disease in Japan: 2007-2012. Pediatrics International: Official Journal of the Japan Pediatric Society, 58, 1140-1145. https://doi.org/10.1111/ped.12970

[14] Kim, G.B., Park, S., Eun, L.Y., Han, J.W., Lee, S.Y., et al. (2017) Epidemiology and Clinical Features of Kawasaki Disease in South Korea, 2012-2014. The Pediatric Infectious Disease Journal, 36, 482-485. https://doi.org/10.1097/INF.0000000000001474

[15] Huang, Y.-H., Lin, K.-M., Ho, S.-C., Yan, J.-H., Lo, M.-H. and Kuo, H.-C. (2019) Increased Incidence of Kawasaki Disease in Taiwan in Recent Years: A 15 Years Nationwide Population-Based Cohort Study. Frontiers in Pediatrics, 7, 121. https://doi.org/10.3389/fped.2019.00121

[16] Du, Z.D., Zhao, D., Du, J., Zhang, Y.L., Lin, Y., Liu, C. and Zhang, T. (2007) Epidemiologic Study on Kawasaki Disease in Beijing from 2000 through 2004. The Pediatric Infectious Disease Journal, 26, 449-451. https://doi.org/10.1097/01.inf.0000261196.79223.18

[17] Ng, Y.M., Sung, R.Y., So, L.Y., Fong, N.C., Ho, M.H., Cheng, Y.W., Lee, S.H., Mak, W.C., Wong, D.M., Yam, M.C., et al. (2005) Kawasaki Disease in Hong Kong, 1994 to 2000. Hong Kong Medical Journal, 11, 331-335.

[18] Cheung, Y.F. (2012) Kawasaki Disease in Hong Kong 2000-2011. 10th International Kawasaki Disease Symposium: From Genetics to Clinics, Kyoto, 7-10 February 2012, 42-43. http://www.blackwellpublishing.com/journals/PED

[19] Holman, R.C., Belay, E.D., Christensen, K.Y., Folkema, A.M., Steiner, C.A. and Schonberger, L.B. (2010) Hospitalizations for Kawasaki Syndrome among Children in the United States, 1997-2007. The Pediatric Infectious Disease Journal, 29, 483-488. https://doi.org/10.1097/INF.0b013e3181cf8705

[20] Lynch, M., Holman, R.C., Mulligan, A., Belay, E.D. and Schonberger, L.B. (2003) Kawasaki Syndrome Hospitalizations in Ireland, 1996 through 2000. The Pediatric Infectious Disease Journal, 22, 959-963. https://doi.org/10.1097/01.inf.0000095194.83814.ee

[21] Saundankar, J., Yim, D., Itotoh, B., Payne, R., Maslin, K., et al. (2014) The Epidemiology and Clinical Features of Kawasaki Disease in Australia. Pediatrics, 133, e1009. https://doi.org/10.1542/peds.2013-2936

[22] Heaton, P., Wilson, N., Nicholson, R., Doran, J., Parsons, A. and Aiken, G. (2006) Kawasaki Disease in New Zealand. Journal of Paediatrics and Child Health, 42, 184-190. https://doi.org/10.1111/j.1440-1754.2006.00827.x

[23] Uehara, R. and Belay, E.D. (2012) Epidemiology of Kawasaki Disease in Asia, Europe, and the United States. Journal of Epidemiology, 22, 79-85. https://doi.org/10.2188/jea.JE20110131

[24] Lee, H. and Shin, J. (2017) Myocardial Assessment in School-Aged Children with Past Kawasaki Disease. Journal of Korean Medical Science, 32, 1835-1839. https://doi.org/10.3346/jkms.2017.32.11.1835

[25] Song, R., Yao, W. and Li, X. (2017) Efficacy of Four Scoring Systems in Predicting Intravenous Immunoglobulin Resistance in Children with Kawasaki Disease in a 
Children's Hospital in Beijing, North China. The Journal of Pediatrics, 184, 120-124. https://doi.org/10.1016/j.jpeds.2016.12.018

[26] Rigante, D., Andreozzi, L., Fastiggi, M., Bracci, B., Natale, M.F. and Esposito, S. (2016) Critical Overview of the Risk Scoring Systems to Predict Non-Responsiveness to Intravenous Immunoglobulin in Kawasaki Syndrome. International Journal of Molecular Sciences. 17, 278-278. https://doi.org/10.3390/ijms17030278

[27] Xue, L.J., Wu, R., Du, G.L., Xu, Y., Yuan, K.Y., et al. (2017) Effect and Safety of TNF Inhibitors in Immunoglobulin-Resistant Kawasaki Disease: A Meta-Analysis. Clinical Reviews in Allergy \& Immunology, 52, 389-400. https://doi.org/10.1007/s12016-016-8581-4

[28] Son, M.B., Gauvreau, K., Ma, L., Baker, A.L., Sundel, R.P., et al. (2009) Treatment of Kawasaki Disease: Analysis of 27 US Pediatric Hospitals from 2001 to 2006. Pediatrics, 124, 1-8. https://doi.org/10.1542/peds.2008-0730

[29] Furukawa, T., Kishiro, M., Akimoto, K., Nagata, S., Shimizu, T. and Yamashiro, Y. (2008) Effects of Steroid Pulse Therapy on Immunoglobulin-Resistant Kawasaki Disease. Archives of Disease in Childhood, 93, 142-146. https://doi.org/10.1136/adc.2007.126144

[30] Sonoda, K., Mori, M., Hokosaki, T. and Yokota, S. (2014) Infliximab plus Plasma Exchange Rescue Therapy in Kawasaki Disease. The Journal of Pediatrics, 164, 1128-1132.e1. https://doi.org/10.1016/j.jpeds.2014.01.020

[31] Portman, M.A., et al. (2019) Etanercept with IVIg for Acute Kawasaki Disease: A Randomized Controlled Trial. Pediatrics, 143, e20183675. https://doi.org/10.1542/peds.2018-3675

[32] Burns, J.C., Kone-Paut, I., Kuijpers, T., Shimizu, C., Tremoulet, A. and Arditi, M. (2017) Review: Found in Translation: International Initiatives Pursuing Interleukin-1 Blockade for Treatment of Acute Kawasaki Disease. Arthritis \& Rheumatology (Hoboken, N/), 69, 268-276. https://doi.org/10.1002/art.39975

[33] Dusser, P. and Kone-Paut, I. (2017) IL-1 Inhibition May Have an Important Role in Treating Refractory Kawasaki Disease. Frontiers in Pharmacology, 8, 163. https://doi.org/10.3389/fphar.2017.00163

[34] Newburger, J.W., Takahashi, M., Gerber, M.A., Gewitz, M.H., Tani, L.Y., et al. (2004) Diagnosis, Treatment, and Long-Term Management of Kawasaki Disease: A Statement for Health Professionals from the Committee on Rheumatic Fever, Endocarditis and Kawasaki Disease, Council on Cardiovascular Disease in the Young, American Heart Association. Circulation, 110, 2747-2771. https://doi.org/10.1161/01.CIR.0000145143.19711.78

[35] Kaida, Y., Kambe, T., Kishimoto, S., Koteda, Y., Suda, K., et al. (2017) Efficacy and Safety of Plasma Exchange for Kawasaki Disease with Coronary Artery Dilatation. Renal Replacement Therapy, 3, 50. https://doi.org/10.1186/s41100-017-0130-y

[36] Noguchi, S., Saito, J., Kudo, T., Hashiba, E. and Hirota, K. (2018) Safety and Efficacy of Plasma Exchange Therapy for Kawasaki Disease in Children in Intensive Care Unit: Case Series. JA Clinical Reports, 4, 25. https://doi.org/10.1186/s40981-018-0156-3

[37] Wallace, C.A., French, J.W., Kahn, S.J. and Sherry, D.D. (2000) Initial Intravenous Gammaglobulin Treatment Failure in Kawasaki Disease. Pediatrics, 105, E78. https://doi.org/10.1542/peds.105.6.e78

[38] Suzuki, H., Terai, M., Hamada, H., Honda, T., Suenaga, T., et al. (2011) Cyclosporin A Treatment for Kawasaki Disease Refractory to Initial and Additional Intravenous 
Immunoglobulin. The Pediatric Infectious Disease Journal, 30, 871-876.

https://doi.org/10.1097/INF.0b013e318220c3cf

[39] Jang, H., Kim, K.Y. and Kim, D.S. (2018) Clinical Outcomes of Low-Dose Methotrexate Therapy as a Second-Line Drug for Intravenous Immunoglobulin-Resistant Kawasaki Disease. Yonsei Medical Journal, 59, 113-118.

https://doi.org/10.3349/ymj.2018.59.1.113 